\title{
Novel Strategies to Increase Sodium Removal and to Reduce Glucose Exposures in Peritoneal Dialysis
}

\author{
${ }^{1}$ Department of Nephrology, Italy \\ ${ }^{2}$ Department of Nephrology and Dialysis, Italy \\ ${ }^{3}$ Department of Medicine, Italy \\ ${ }^{4}$ CoreQuest, R\&D Department, Switzerland \\ ${ }^{5}$ Division of Renal Medicine, Department of Clinical Science, Sweden \\ *Corresponding author: Borrelli S, Department of Nephrology, Italy
}

Borrelli $S^{* 1}$, Garofalo $C^{1}$, Peruzzu $\mathbf{N}^{1}$, Polese $\mathbf{L}^{1}$, Netti $A^{1}$, Minutolo $\mathbf{R}^{1}$, De Nicola $\mathbf{L}^{1}$, Provenzano $\mathbf{M}^{1}$, Conte $\mathrm{G}^{1}$, Palumbo $\mathrm{R}^{2}$, Centi $\mathrm{A}^{2}$, Reboldi $\mathrm{G}^{3}$, Bonomini $\mathrm{M}^{1}$, Di Liberato $\mathrm{L}^{4}$, Arduini A4 and Divino JC ${ }^{5}$

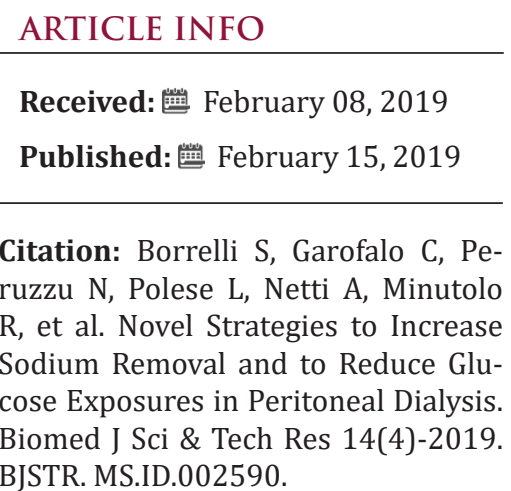

ABSTRACT

Keywords: Peritoneal Dialysis; Low-Sodium Dialysate; Glucose-Sparing Dialysate

Abbreviations: PD: Peritoneal Dialysis; DSR: Dialytic Sodium Removal; CAPD: Continuous Ambulatory PD; APD: Automated PD

\section{Mini Review}

The success of Peritoneal Dialysis (PD) as renal replacement treatment is mainly due to the achievement of dialysis adequacy with a good adaptability to the patients' needs. Adequate sodium and fluid balance are basic requirements to successfully prolong technique survival and to improve the patient survival [1]. Therefore, while keeping in mind that restriction of salt and fluid intake, appropriate diuretic therapy, preservation of residual diuresis and peritoneal membrane functions are of paramount importance to achieve sodium balance. It is similarly important to highlight current and future PD strategies to optimize sodium removal through peritoneal membrane. A recent meta-analysis of observational studies comparing dialytic sodium removal (DSR) achieved by Continuous Ambulatory PD (CAPD) and automated PD (APD) in current clinical practice, showed that CAPD allows to remove a mean of $141 \mathrm{mmol}$ of sodium per day with a strict correlation between sodium and fluid removal.
Conversely, the amount of sodium removed by APD is lower (86 mmol/day) despite a similar fluid removal [2]. In the early nineties the use of lower sodium dialysate had been proposed as potential strategy to rise the concentration gradient between blood and dialysate and thereby increasing sodium removal by diffusion, which is negligible when conventional solutions are used [3]. Earlier studies showed that dialysis solutions with a sodium concentration of approximately 100 $\mathrm{mmol} / \mathrm{L}$ were able to increase sodium removal up to three times more than conventional fluid, but with less effect on fluid removal because of the reduction of solution osmolarity and increased risk of hyponatremia (glucose-uncompensated solutions) [4-6]. Furthermore, Davies et al. after comparing conventional solutions with low sodium glucose-compensated (115 mmol/L) and ultralow sodium glucose-uncompensated (102 mmol/L), respectively, suggested that low-sodium solutions should have a compensatory 
increase in osmolarity to maintain sufficient ultrafiltration, even though this strategy may increase glucose load [7]. More recently, Rutkowski et al. [8] using a PD solution with a mildly reduced sodium content of $125 \mathrm{mmol} / \mathrm{L}$ and unchanged levels of glucose have reported a decrement of BP levels, suggesting that these PD solutions may be a worthy alternative to standard solutions for hypertensive long-term PD patients [8].

An additional therapeutic strategy to enhance fluid and sodium removal may be the use of a combinations of a mixed crystalloid and colloid PD fluid (bimodal solution) obtained by mixing glucose and icodextrinwith a final concentration of 2.6 and $6.8 \%$, respectively, allowing to achieve a well-maintained osmolarity and low-sodium solution (121 mmol/L). Freida et al. [9] reported that such bimodal solution, used once daily, allowed a significant increase of sodium and fluid removal with reduced exposure of peritoneum to glucose [9]. The concept of UF efficiency, defined as the amount of net UF obtained for every gram of carbohydrate absorbed from the dialysis solution, has been enhanced in this study with a $71 \% \mathrm{UF}$ efficiency increase in the bimodal solution, as consequence of a 2.5 fold enhancement of daytime UF. Bimodal UF might be a powerful glucose-sparing strategy for volume control for PD patients [9]. Further novel strategy to increase DSR may be the "twice-daily icodextrin". Generally, icodextrin is applied once daily to prevent accumulation of icodextrin metabolites, mainly maltose.

Some authors have been reported an improvement of UF on the short-term by use of icodextrin twice-daily dose (i.e., two exchanges per day) in particular setting of patients with UF failure [10]. Additional to low sodium PD solutions, lowering the total intraperitoneal glucose load could be equally clinically relevant for PD patients. Promising results come from a peritoneal dialysate solution which contains L-carnitine and xylitol together with a reduced amount of glucose. The biocompatibility of this solution was confirmed by Bonomini et al. in experimental studies on human umbilical vein endothelial cells [11]. The use of xylitol, a sugar substitute of glucose, already used in parenteral nutrition, is safe and allows a reduction of the glucose concentration in PD solutions with no reduction of the crystalloid osmotic effect. A further reduction in glucose concentration in the dialysate, with no detrimental effect on the UF profile, may be achieved through the addition of L-carnitine [11], a naturally occurring compound that might have added beneficial effects on glucose homeostasis

\section{ISSN: 2574-1241}

DOI: 10.26717.BJSTR.2019.14.002590

Borrelli S. Biomed J Sci \& Tech Res

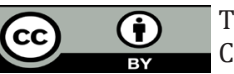

This work is licensed under Creative Commons Attribution 4.0 License

Submission Link: https://biomedres.us/submit-manuscript.php and insulin sensitivity in PD patients [12]. In conclusion, the combination of these two strategies would allow the formulation of low sodium PD solutions, whereby the need to compensate the reduction of the osmotic strength reduction can be achieved with more biocompatible crystalloid agents than glucose like xylitol and L-carnitine.

\section{References}

1. Van Biesen W, Heimburger O, Krediet R, Rippe B, La Milia V, et al. (2010) Evaluation of peritoneal membrane characteristics: clinical advice for prescription management by the ERBP working group. Nephrol Dial Transplant 25(7): 2052-2062.

2. Borrelli S, La Milia V, De Nicola L, Cabiddu G, Russo R, et al. (2018) Sodium removal by peritoneal dialysis: a systematic review and metaanalysis. J Nephrol.

3. Wang T, Waniewski J, Heimbürger O, Werynski A, Lindholm B (1997) A quantitative analysis of sodium transport and removal during peritoneal dialysis. Kidney Int 52(6): 1609-1616.

4. Imholz AL, Koomen GC, Struijk DG, Arisz L, Krediet RT (1994) Fluid and solute transport in CAPD patients using ultralow sodium dialysate. Kidney Int 46(2): 333-340.

5. Leypoldt JK, Charney DI, Cheung AK, Naprestek CL, Akin BH, et al. (1995) Ultrafiltration and solute kinetics using low sodium peritoneal dialysate. Kidney Int 48(6): 1959-1966.

6. Nakayama M, Kasai K, Imai H (2009) Novel low Na peritoneal dialysis solutions designed to optimize $\mathrm{Na}$ gap of effluent: kinetics of $\mathrm{Na}$ and water removal. Perit Dial Int 29(5): 528-535.

7. Davies S, Carlsson O, Simonsen O, Ann Cathrine Johansson, Daniele Venturoli, et al. (2009) The effects of low-sodium peritoneal dialysis fluids on blood pressure, thirst and volume status. Nephrol Dial Transplant 24(5): 1609-1617.

8. Rutkowski B, Tam P, van der Sande FM, Vychytil A, Schwenger V, et al. (2016) Low-Sodium Versus Standard-Sodium Peritoneal Dialysis Solution in Hypertensive Patients: A Randomized Controlled Trial. Am J Kidney Dis 67(5): 753-761.

9. Freida P, Wilkie M, Jenkins S, Dallas F, Issad B (2008) The contribution of combined crystalloid and colloid osmosis to fluid and sodium management in peritoneal dialysis. Kidney Int Suppl (108): S102-11.

10. Bonomini M, Di Silvestre S, Di Tomo P, Di Pietro N, Mandatori D, et al. (2016) Effect of peritoneal dialysis fluid containing osmo-metabolic agents on human endothelial cells. Drug Des Devel Ther 10: 3925-3932.

11. Bonomini M, Pandolfi A, Di Liberato L, Sara Di Silvestre, Yvette Cnops, et al. (2011) L-carnitine is an osmotic agent suitable for peritoneal dialysis. Kidney Int 80(6): 645-654.

12. Bonomini M, Di Liberato L, Del Rosso G, Stingone A, Marinangeli G, et al. (20013) Effect of an L-carnitine-containing peritoneal dialysate on insulin sensitivity in patients treated with CAPD: a 4-month, prospective, multicenter randomized trial. Am J Kidney Dis 62(5): 929-938.

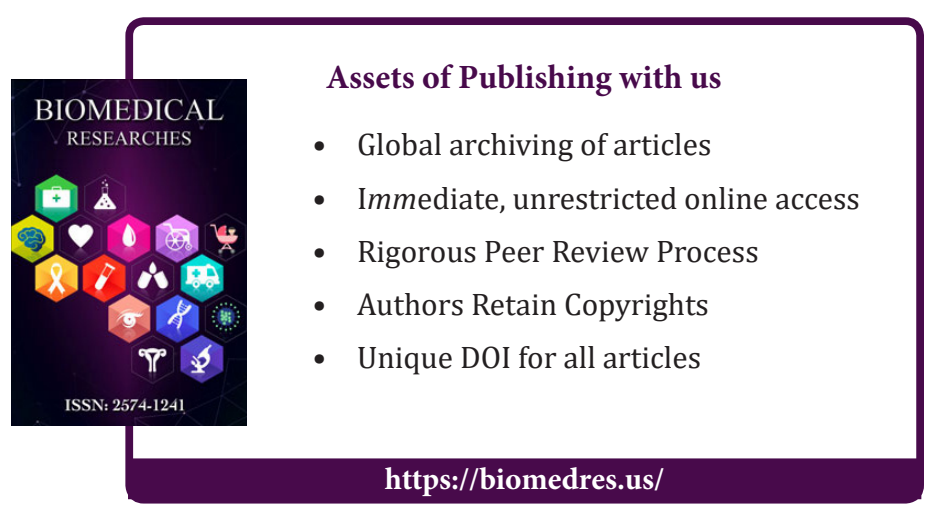

